\title{
Exendin-4 Normalizes Islet Vascularity in Intrauterine Growth Restricted Rats: Potential Role of VEGF
}

\author{
J. NINA HAM, MICHAEL F. CRUTCHLOW, BIVA M. DESAI, REBECCA A. SIMMONS, AND DORIS A. STOFFERS \\ Department of Medicine and the Institute for Diabetes, Obesity, and Metabolism [J.N.H., M.F.C., B.M.D., D.A.S.]; Department of \\ Pediatrics [J.N.H., R.A.S.], University of Pennsylvania School of Medicine, Philadelphia, Pennsylvania 19104
}

\begin{abstract}
Intrauterine growth restriction (IUGR) induced by uterine artery ligation in pregnant rats leads to low birth weight and early insulin secretory defects followed by the development of insulin resistance, decline in $\beta$-cell mass, and diabetes in adulthood. Neonatal administration of Exendin-4 (Ex-4) prevents the deterioration of $\beta$-cell mass and the onset of adult-onset diabetes. Our aim was to determine whether this effect occurs through preservation of islet vascularization. In 2 wk-old IUGR rats, endothelial-specific lectin staining revealed a $40 \%$ reduction in islet vascular density ( $p=$ 0.027 ), which was normalized by neonatal Ex-4. VEGF-A protein expression was reduced in IUGR islets compared with controls at postnatal d 1 (P). Neonatal Ex-4 normalized islet VEGF protein expression at P7. Neither IUGR nor Ex-4 administration to IUGR rats affected relative VEGF splice isoform RNA levels. Together, the reduced vascularity in IUGR islets before the deterioration of $\beta$-cell mass, and the enhancement of VEGF expression and normalization of islet vascularity by neonatal Ex-4, suggest islet vascularity as an early determinant of $\beta$-cell mass and as a potential therapeutic target for diabetes prevention. (Pediatr Res 66: 42-46, 2009)
\end{abstract}

$\mathrm{U}$ teroplacental insufficiency, leading to reduced delivery of nutrients, oxygen, growth factors, and hormones to the developing fetus, is a common cause of fetal growth restriction. Epidemiologic studies in humans have established a correlation between intrauterine growth restriction (IUGR) and an increased risk of type 2 diabetes, obesity, and coronary artery disease in later life (1). This demonstration of the fetal origins hypothesis, the idea that the fetal environment has a crucial influence on development of adult-onset disease, has been reproduced in multiple human populations and in various animal models (1). In a rat model of uteroplacental insufficiency, bilateral uterine artery ligation in late gestation results in IUGR and low birth weight (2). IUGR rats develop a phenotype similar to that of type 2 diabetes in humans, with the development of obesity, insulin resistance, and insulinsecretory deficits. Although normal early in life, there is a progressive decline in $\beta$-cell mass of IUGR rats, preceding the

Received July 7, 2008; accepted February 12, 2009

Correspondence: Doris A. Stoffers, M.D., Ph.D., Division of Endocrinology, Diabetes, and Metabolism, Department of Medicine, Clinical Research Building 726, University of Pennsylvania School of Medicine, 415 Curie Boulevard, Philadelphia, PA 19104; e-mail: stoffers@mail.med.upenn.edu

Supported by NIH R01 DK06296502 (D.A.S. and R.A.S.) and a Lawson Wilkins Pediatric Endocrine Society Research Fellowship and NIH National Research Service Award F32 DK074299-01 (J.N.H.). Supported by the Morphology Core of the University of Pennsylvania Center for Molecular Studies in Digestive and Liver Disease (P30-DK-50306).

R. A. S. and D. A. S. share equal senior author status on this work. development of hyperglycemia and diabetes by several weeks of age (2).

Extensive islet remodeling occurs during the immediate postnatal period in rodent pancreatic development, with waves of $\beta$-cell proliferation, apoptosis, and neogenesis in the first weeks of life $(3,4)$. Similar to the impact that a negative fetal environment has on future pancreatic function, therapeutic intervention within this critical neonatal period may permanently improve $\beta$-cell mass throughout adulthood. The incretin hormone glucagon-like peptide-1 (GLP-1) and the long-acting GLP-1 receptor agonist, Exendin-4 (Ex-4), augment insulin secretion and improve glucose tolerance in diabetes (5). GLP-1 also promotes expansion of $\beta$-cell mass by increasing proliferation and stimulating neogenesis (5). Importantly, Ex-4 when given in the neonatal period has been shown to prevent the reduction of $\beta$-cell mass in the IUGR rat, thus completely averting the development of adult-onset diabetes (6).

The islets of Langerhans possess a rich capillary network with increased fenestrations that sustain extensive blood flow compared with the surrounding exocrine tissue (7). Vascular endothelium also provides critical signals that induce endocrine pancreatic differentiation and growth. In vivo, adjacent endothelium is required for early pancreatic bud formation, and in vitro, coculture of endodermal explants with portions of aortic endothelium are sufficient to induce the pancreatic progenitor marker Ptfla and insulin gene expression $(8,9)$. In turn, islets express VEGF, a potent angiogenic growth factor that acts via flt-1 and flk-1, high affinity VEGF receptors expressed by islet endothelial cells (9-12). Overexpression of VEGF driven by the $P d x l$ promoter in transgenic mice leads to increased vascular endothelium and islet hyperplasia (9). Conversely, global pancreas-specific and $\beta$-cell-specific deletions of VEGF result in reduced islet endothelial cell area or vessel density, abnormal endothelial cell morphology, and impaired glucose tolerance $(13,14)$.

We investigated the mechanisms by which IUGR and neonatal Ex-4 treatment modulate $\beta$-cell mass and found that islet vascular density is reduced early on in IUGR islets. Further, islet vascular density was normalized in IUGR rats treated with Ex-4 during the neonatal period. These changes are mediated at least in part by regulation of the angiogenic factor

\footnotetext{
Abbreviations: AFI, average fluorescence intensity; BS1, B. simplicifolia 1; Ex-4, Exendin-4; GLP-1, glucagon-like peptide-1; P, postnatal day; QPCR, quantitative PCR; Veh, vehicle
} 
VEGF, as VEGF protein expression was reduced in early postnatal IUGR islets, and Ex-4 treatment enhanced pancreatic VEGF protein expression. These observations were supported by similar changes in VEGF mRNA levels at $1 \mathrm{wk}$ of age, but were not due to alterations in VEGF mRNA splicing.

\section{METHODS}

Animal model. To induce IUGR in Sprague-Dawley rats (Charles River Laboratories, Wilmington, MA), maternal uterine arteries were surgically ligated at $19 \mathrm{~d}$ gestation as previously described (2). Sham-operated animals served as controls. Animals were chow-fed ad libitum, and housed under conventional conditions. After delivery, litters were culled to eight pups per litter. Four experimental groups were studied: 1) sham control pups, vehicle treated (1\% BSA in normal saline); 2) sham pups, Ex-4 treated [1 $\mathrm{nmol} / \mathrm{kg} / \mathrm{d}$, s.c., on postnatal d 1-6], 3) IUGR pups, vehicle treated, 4) IUGR pups, Ex-4 treated ( $n=9$ litters per experimental group). Pancreata were harvested for analysis at postnatal days 1 (P1), 7, and 14. Studies were approved by the Animal Care and Use Committees of the University of Pennsylvania School of Medicine and the Children's Hospital of Philadelphia.

Immunohistochemistry. Islet vascularity was assessed by direct staining of sections with Bandeiraea simplicifolia (BS1) lectin (Vector Laboratories; Burlingame, CA). For BS1 staining, immunohistochemistry was performed on paraffin-embedded rat pancreas tissue sections $(n=4$ animals). After microwave antigen retrieval, slides were incubated overnight in $0.1 \mathrm{U} / \mathrm{mL}$ neuraminidase (Sigma Chemical Co., St. Louis, MO) in $0.1 \%$ calcium chloride, $0.1 \mathrm{M}$ sodium acetate. Biotinylated BS1 Lectin 1 Isolectin B4 (Vector Laboratories) was applied at a 1:50 dilution in $0.1 \%$ $\mathrm{CaCl}, 00.05 \mathrm{M}$ TBS, pH 7.7 overnight at $4^{\circ} \mathrm{C}$. Tissue sections were incubated with HRP-conjugated streptavidin (Vector Laboratories) followed by DAB (DAB Substrate Kit for Peroxidase, Vector Laboratories) as previously described (15).

For VEGF immunofluorescence staining, paraffin-embedded sections of pancreas $(n=4)$ were microwaved in $10 \mathrm{mM}$ citric acid for antigen-retrieval. Tissue sections were then costained for VEGF (1:400, Oncogene Research Products, San Diego, CA) and insulin (1:1000, Linco Research, St. Charles, MO), glucagon (1:500, Santa Cruz Biotechnology, Santa Cruz, CA), or somatostatin (1:1000, Santa Cruz Biotechnology), and visualized with Cy2 and Cy3-coupled secondary antisera (Jackson ImmunoResearch Laboratories, Inc., West Grove, PA).

Quantification of islet vascularity. To calculate percent of islet area occupied by BS1 lectin staining, 25 islets per pancreas were imaged with a Cool Snap ${ }_{\mathrm{CF}}$ black and white CCD camera using IP Lab Software (Spectra Services; Webster, NY). Images were captured with the Black and White Same Exposure program with flat-field correction at a magnification of $400 \times$. After capturing each islet as a single frame, all images from a given pancreas were converted into a sequence form and then adjusted to match a chosen standard intensity obtained from a representative islet from the set. The percent area within an islet occupied by lectin staining was determined by designating the islet as a region of interest (ROI) using the drawing tool and then adjusting segmentation to cover the full extent of lectin staining within the ROI. The percent of lectin stained segmented area within the ROI was calculated using the "Quantify Segments" function.

Western blot analysis and quantification of protein expression. Pancreas was harvested and protein was isolated by sonication in SDS-lysis buffer (50 $\mathrm{mM}$ Tris, $2 \%$ SDS, $10 \%$ glycerol, $10 \mathrm{mM}$ sodium pyrophosphate, $100 \mathrm{mM}$ sodium fluoride, $6 \mathrm{M}$ urea, $10 \mathrm{mM}$ EDTA). Total protein was quantified by Micro BCA protein assay (Pierce Biotechnology Inc, Rockford, IL). Western blot analysis of VEGF (1:1000; Oncogene Research Products, San Diego, CA) and cyclophilin B (1:20,000; Affinity Bioreagents, Golden, CO) expression was performed on total pancreatic protein lysates. Densitometric analysis was performed using Scion Image software (Scion, Frederick, M.D.).

RNA Isolation and real-time PCR. RNA was isolated from isolated islets or total pancreata using the Trizol method of RNA extraction (Invitrogen, Carlsbad, CA). RNA integrity and quantity were assessed using the Agilent 2100 Bioanalyzer with the RNA 6000 Nano Chip (Agilent Technologies, Wilmington, DE). Total RNA was reverse transcribed to cDNA (First-Strand cDNA Synthesis Kit, Amersham Biosciences, Piscataway, NJ) and quantitative real-time PCR (QPCR) for VEGF and $\beta$-actin was performed using the MyIQ Single-Color Real-Time PCR Detection System (BioRad Laboratories, Hercules, CA) as previously described (16). Results were expressed relative to the $\beta$-actin control, and then expressed as a fold change above the respective control samples in the same PCR. Forward and reverse primers for VEGF amplification were 5'CGATTTGTTTGTCCAAGA3' and 5'GAACGTCTAGACTGTTCGGTTCC3', respectively.

VEGF splice isoform identification. Reverse transcription PCR was performed using primers specifically designed to amplify the major rodent VEGF splice isoforms. The forward and reverse primers ( $5^{\prime}$ GGACCCTGACTTTACTGCTGTACC3' and 5'CACCGCCTTTTCTCACAT3') were designed to recognize sequences in exons 1 and 8 of the rat VEGF gene. Both exons 1 and 8 are common to all angiogenic VEGF splice isoforms, and the PCR resulted in amplicons with lengths of $616 \mathrm{bp}, 564 \mathrm{bp}$, and $412 \mathrm{bp}$, corresponding to the transcripts encoding $\mathrm{VEGF}_{188}, \mathrm{VEGF}_{164}$, and $\mathrm{VEGF}_{120}$, respectively. The resulting PCR products were quantified using the Agilent 2100 Bioanalyzer and the DNA 1000 Labchip (Agilent Technologies), which profile DNA samples by size $(25-1000 \mathrm{bp})$ and quantity $(0.1-50 \mathrm{ng} / \mu \mathrm{L})$. Linearity was confirmed over 30 cycles of PCR amplification along a spectrum of cDNA template concentrations (25-200 ng/ $\mu \mathrm{L}$ RNA equivalent) within the range of our experimental parameters.

Statistical analyses. Data are presented as mean \pm SEM, unless otherwise noted. Statistical comparisons were performed using the $t$ test or two-way ANOVA, with cut-off for significance being $p<0.05$.

\section{RESULTS}

Islet vascularity is reduced in IUGR and normalized by $\boldsymbol{E x}-\mathbf{4}$ administration. As vascular endothelium is crucial to islet growth and function, we hypothesized that islet vascularity is reduced in islets of IUGR rats at a young age, before $\beta$-cell mass begins to deteriorate, and that early intervention with Ex-4 prevents this reduction. We used an endothelial specific lectin, BS1, to directly assess islet vascularity. IUGR islets showed a reduced density of vascular endothelium at 2 weeks of age (Fig. 1A). Most interesting was the apparent normalization of vessel density by previous treatment with Ex-4 during the neonatal period. When islet vascular density was quantitated as shown in Figure 1B, we observed a $40 \%$ reduction in the percent area of lectin staining in IUGR islets $(7.47 \pm 0.75 \%$ compared with $12.39 \pm 1.35 \%$ in control +
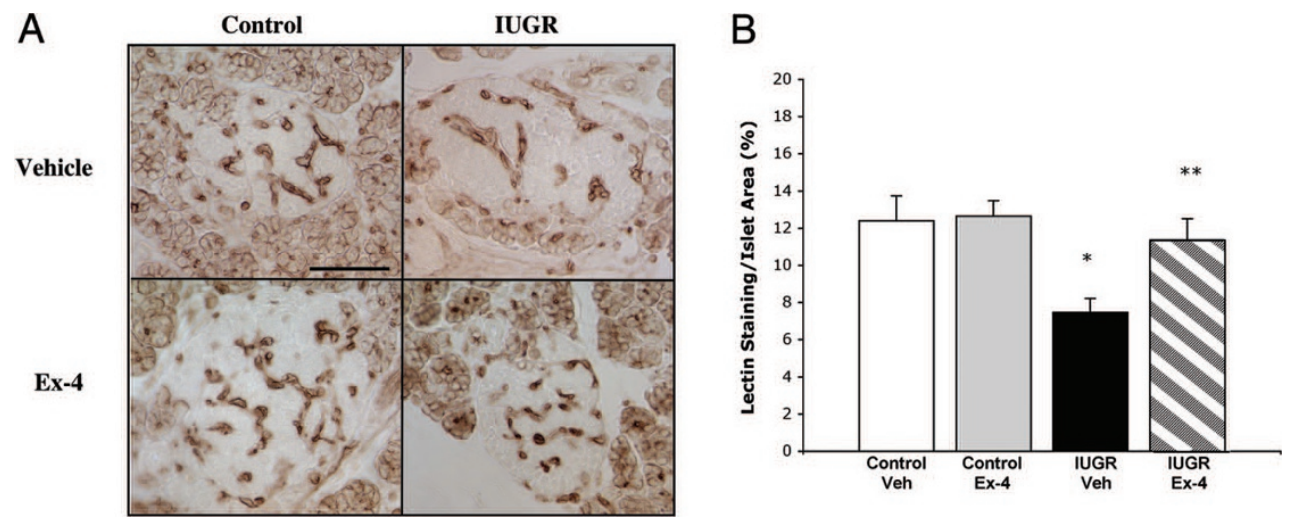

Figure 1. Reduction in IUGR islet vascular density is normalized by neonatal Exendin-4 administration. (A) Immunohistochemistry for biotinylated $B$. simplicifolia lectin to visualize the islet capillary network in pancreatic sections from 2-wk-old control and IUGR rats treated with vehicle or Ex-4 during the neonatal period. (B) Quantification of islet vessel density in 25 islets per pancreas ( $n=4$ pancreata per treatment group); ${ }^{*} p<0.05$ compared with control + Veh; $* * p<0.05$ compared with IUGR + Veh while $p=$ NS compared with control + Veh. The size bar represents $25 \mu \mathrm{m}$. 
Veh, $p=0.027)$, with normalization in the IUGR + Ex-4 group $(11.37 \pm 1.14 \%, p=$ NS compared with control + Veh). Of note, Ex-4 did not increase islet vascularity above control levels in sham-operated control offspring.

Islet VEGF expression is localized to $\beta$ and $\alpha$ cells. To explore potential mechanisms underlying these changes in islet vascularity, we examined the expression of the angiogenic factor VEGF-A. As previously noted by others, VEGF within the pancreas was localized predominantly to islets $(11,13,17,18)$. VEGF staining was cytoplasmic and colocalized with insulin in $\beta$ cells (Fig. $2 A$ ), but was also present within a rim of non- $\beta$ islet cells. Double immunofluorescence

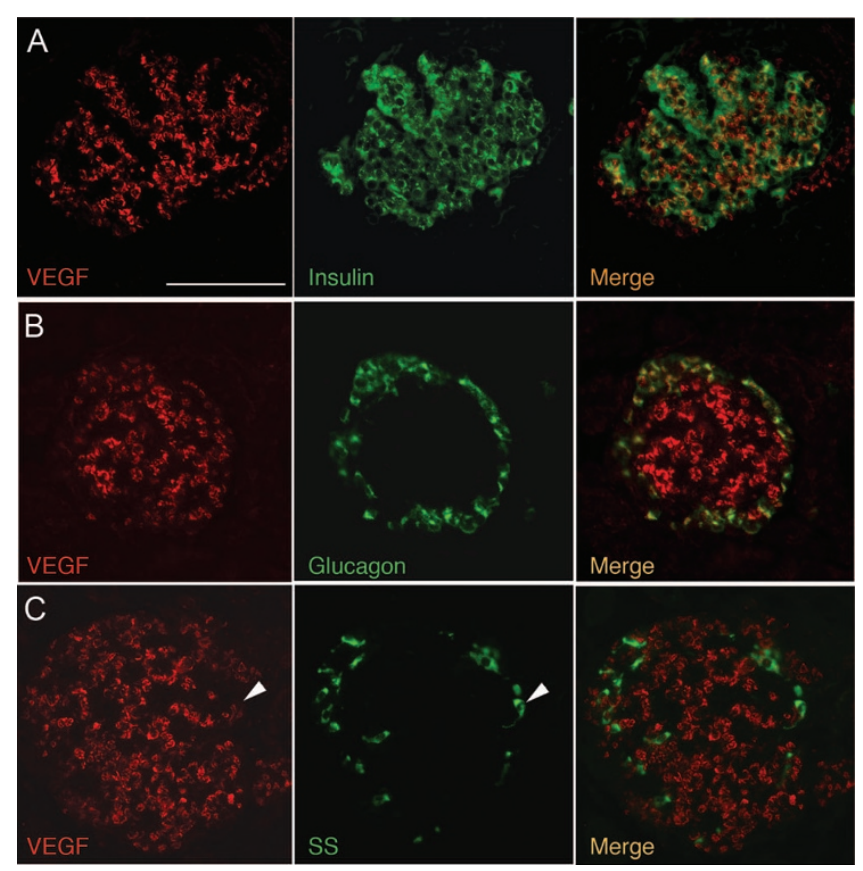

Figure 2. VEGF is primarily expressed within $\beta$ cells of the pancreatic islet. Double immunofluorescence detection of VEGF (red) with $(A)$ insulin (green), (B) glucagon (green), or $(C)$ somatostatin (green) in pancreas sections from neonatal rat pups at $7 \mathrm{~d}$ of age. Right panels represent merged images. Arrowheads indicate the location of a $\delta$ cell that does not stain for VEGF. Pictured are representative images at $\times 200$ magnification, $n=4$ animals. The size bar represents $50 \mu \mathrm{m}$. with glucagon revealed expression of VEGF within $\alpha$ cells (Fig. $2 B$ ). In contrast, little or no VEGF was observed in $\delta$ cells (Fig. 2C). In contrast to previous studies, we did not observe substantial VEGF staining in the surrounding exocrine tissue $(10,11)$.

IUGR attenuates early postnatal islet VEGF expression, whereas Ex-4 increases VEGF expression in IUGR islets. At P1, by immunofluorescent staining, VEGF protein levels within IUGR islets were reduced compared with control islets (Fig. 3A). We performed Western blot analysis to assess quantitatively the extent of VEGF regulation in the setting of IUGR and Ex-4 administration. Because the procedure of islet isolation results in hypoxic induction of VEGF expression and potential loss of in vivo regulation $(19,20)$, whole pancreata from 1-wk-old rats were harvested for Western blot analysis of VEGF protein. After normalization to cyclophilin expression, VEGF protein was reduced in pancreas from IUGR rats compared with sham-operated controls $(0.45 \pm 0.08$ vs. $0.91 \pm 0.13, p<0.02$ ) (Fig. 3B). Ex-4 treatment restored VEGF protein levels of IUGR animals to that of controls $(0.75 \pm 0.07 v s .0 .91 \pm 0.13, p=\mathrm{NS})$ (Fig. $3 B)$, mirroring the previous islet vascular density findings.

Next, we sought to determine whether increased VEGF protein expression within IUGR animals was due to altered transcription of the VEGF gene. Analysis of steady-state VEGF RNA and protein levels in isolated islet preparations at P7 showed no differences among the four experimental groups ( $n=3$ litters per condition, data not shown), likely the result of the hypoxic stimulus inherent to the islet isolation process masking differences in VEGF expression. To minimize hypoxic exposure to islets, we examined VEGF levels in mRNA isolated from rapidly dissected total pancreas of IUGR and control rats at P7. By QPCR, we found that VEGF mRNA in IUGR + Veh rat pancreas was comparable with control + Veh levels (Fig. 4A). However, VEGF mRNA level in the IUGR + Ex-4 group was increased by $66 \%$ over control + Veh rats $(p=0.015)$. Although Ex-4 stimulated both VEGF mRNA and immunoreactivity in IUGR animals, we noted a discordance in expression in vehicle-treated IUGR compared with vehicle-treated control animals. This could be due to a
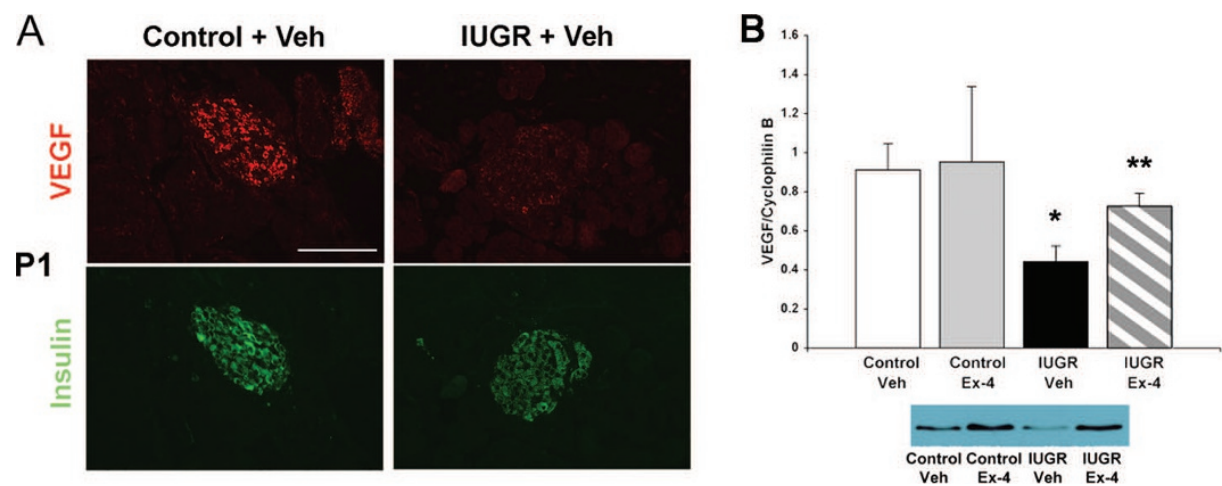

Figure 3. IUGR leads to an early reduction of VEGF in postnatal islets, and Ex-4 administration potentiates islet VEGF expression. (A) Double immunofluorescence for VEGF (red) and insulin (green) in pancreatic sections from IUGR and control rats at postnatal d 1. Ex-4 or vehicle treatment was administered on postnatal days $1-6$. Representative islets are shown $(n=4$ animals per group) at $\times 200$ magnification. $(B)$ Western blot analysis of total pancreas lysates of IUGR and control rats for VEGF at one week of age ( $n=5$ animals per treatment group). Densitometric quantification is expressed relative to cyclophilin $\mathrm{B}, * p<0.02$ compared with control + Veh; $* * p<0.05$ compared with IUGR + Veh and $p=$ NS compared with control + Veh. The size bar represents $25 \mu \mathrm{m}$. 
A

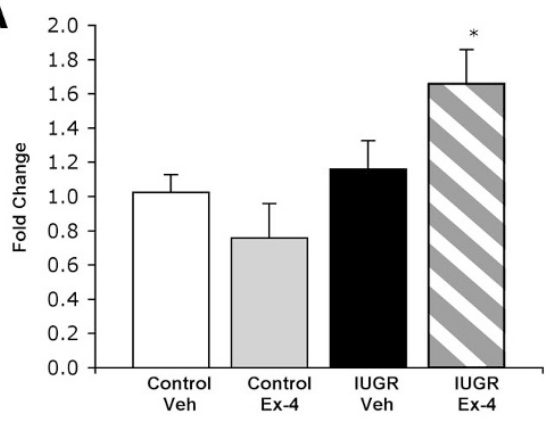

B

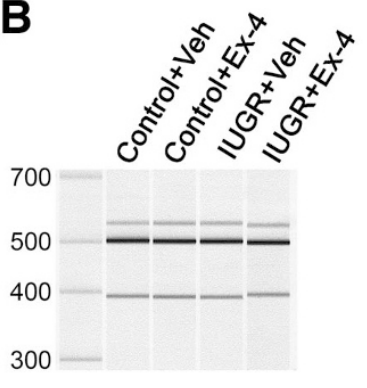

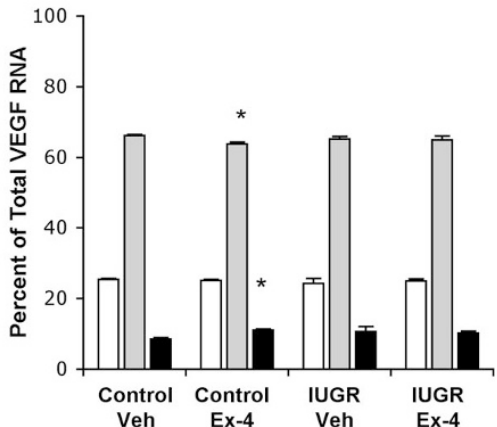

Figure 4. Exendin-4 associated increase in islet VEGF protein expression is due to increased VEGF gene transcription. (A) QPCR analysis of VEGF gene transcript in total pancreas of 1-wk-old IUGR and control rats treated with vehicle or Ex-4 ( $n=3-6$ animals per group). (B) Reverse transcription PCR analysis and quantitation of VEGF splice isoforms. Gel representation of PCR products of various sizes; the left lane represents the molecular weight ladder. PCR products were quantified and expressed as percent contribution of specific isoform to total VEGF transcript $(n=3-6$ animals per group). $* p<0.02$ compared with control + Veh; white bars represent $\mathrm{VEGF}_{120}$; gray bars, $\mathrm{VEGF}_{164}$; black bars, $\mathrm{VEGF}_{188}$.

posttranscriptional mechanism. A recent study by Li et al. (18) examining VEGF expression in the Zucker diabetic fatty (ZDF) rat model also showed discordance between isletspecific VEGF staining and VEGF mRNA levels; treatment of ZDF rats with pioglitazone, while increasing islet endothelial cell area and VEGF staining, actually decreased VEGF mRNA levels.

The QPCR experiments earlier, by design, measured the VEGF splice isoforms $\mathrm{VEGF}_{164}$ and $\mathrm{VEGF}_{188}$, which are the primarily extracellular matrix-bound forms of the VEGF protein. Given the overall increase in $\mathrm{VEGF}_{164}$ and $\mathrm{VEGF}_{188}$ mRNA observed in IUGR + Ex-4 (Fig. 4A), we investigated whether there was a similar increase in all VEGF isoforms, or whether this represented regulation at the level of alternative splicing. By designing PCR primers against the first and last exons, which are common to all VEGF isoforms, we were able to differentiate the variant splice isoforms according to the length of the resultant PCR products. We found that $\mathrm{VEGF}_{120}, \mathrm{VEGF}_{164}$, and $\mathrm{VEGF}_{188}$ were the predominant splice isoforms found in neonatal rat pancreas (Fig. 4B). In all of our experimental groups, $\mathrm{VEGF}_{164}$ constituted approximately $65 \%$ of total VEGF transcript. The relative contribution of each of these isoforms to the total VEGF transcript did not differ among the experimental groups (Fig. 4B) with the exception of a subtle difference in control + Ex-4 animals which showed a minor but statistically significant reduction in $\operatorname{VEGF}_{164}(63.8 \pm$ $0.6 \%$ compared with $66.2 \pm 0.4 \%$ in control + Veh, $p<0.02$ ) with a corresponding increase in $\mathrm{VEGF}_{188}(11.0 \pm 0.3 \%$ compared with $8.46 \pm 0.5 \%$ in control + Veh, $p<0.01$ ).

\section{DISCUSSION}

In an effort to define the factors that determine $\beta$-cell mass in the rat model of IUGR-related diabetes, we explored the relationship between vascular endothelium and pancreatic islets in the neonatal period. The ability of $\beta$-cell mass to expand and compensate for increasing insulin resistance is one of the key determinants in the progression to glucose intolerance and diabetes. In this study, we observed reduced islet vascular density in IUGR rats compared with controls, and we find that neonatal treatment with Ex-4 also normalizes islet vascularity in young IUGR rats. These changes in islet vas- cularity are associated with changes in VEGF expression during the perinatal period. These findings indicate the importance of neonatal vascular development in determining adult $\beta$-cell mass.

Changes in islet vascularity are predictive of altered $\beta$-cell mass. In our previous work, we observed that in the progression to IUGR-related diabetes, $\beta$-cell mass is preserved in early life and deteriorates after $7 \mathrm{wk}$ of age $(2,6)$. Now, we find effects of IUGR and Ex-4 on islet vessel density that precede the reduction of $\beta$-cell mass in IUGR animals by several weeks. This temporal relationship suggests that islet vascularization is a direct determinant of $\beta$-cell mass, a paradigm supported by the ability of vascular endothelium to regulate $\beta$-cell proliferation through direct interaction with integrins on the surface of $\beta$ cells (21). Other experimental diabetes models, including the ZDF rat, have also shown positive correlations between vascularity and islet size or $\beta$-cell mass $(10,18,22)$. These studies, however, did not specifically examine vascularity at time points preceding the changes in islet mass. In this study, our examination of IUGR islets shows that vascular changes precede altered $\beta$-cell mass, and may be a direct determinant of future $\beta$-cell mass.

IUGR reduces islet vascularity and alters VEGF expression. A clear candidate to mediate the effects of IUGR and Ex-4 on islet vascularity is VEGF-A, a potent angiogenic factor that is expressed in pancreatic islets $(9,11,13,17,18,20)$. In the setting of IUGR, VEGF expression was reduced after birth, as was subsequent vascular density measured at 2 weeks. These data are concordant with the studies of lowprotein diet induced IUGR, in which maternal low protein diet reduced islet vascularization and VEGF staining in offspring (10). Although VEGF immunofluorescence was reduced early in IUGR + Veh rats, we observed a return to normal mRNA levels by P7 and normal protein expression by P14.

The discordance between VEGF mRNA and protein levels at P7 led us to postulate that differential expression of the various splice isoforms of VEGF could be a modifying factor, as different isoforms produce varying degrees of local angiogenic stimulus with varying degrees of retention in the surrounding extracellular matrix $(19,23)$. However, we did not observe any major shifts in the balance of VEGF isoform 
expression across our experimental groups. Another possibility is that IUGR induces expression of inhibitory VEGF splice variants, the $\mathrm{VEGF}_{\mathrm{XXXb}}$ family of isoforms, that have been identified in various tissues including human kidney and placenta (24). Finally, it is possible that IUGR induces a down-regulation of VEGF receptors, such as flk-1 and flt-1; however, we assessed expression of flk- 1 and flt- 1 by Western blot analysis at P7 and found no differences among the four experimental groups (data not shown).

Ex-4 administration during the neonatal period increases islet vascularity and induces VEGF expression. Although IUGR reduced islet vascularity, administration of Ex-4 to IUGR rats normalized islet blood vessel density. This correlated with an increase in VEGF mRNA and normalization of protein in IUGR + Ex-4 animals but no major change in the relative amounts of VEGF splice isoforms. Other studies have supported the direct importance of VEGF in determining not only islet vascularization but also islet size; transgenic overexpression of VEGF alone in pancreatic islets is sufficient to induce islet hypervascularity and islet hyperplasia (14).

Interestingly, Ex-4 did not increase vascular density above control levels in sham-operated rats, suggesting the presence of homeostatic mechanisms to prevent hypervascularity, which might otherwise be a precursor of malignancy. At the transcriptional level, there was a slight shift in the ratio of VEGF isoforms in the Ex-4-treated control rats. Although statistically significant, this difference is minor in absolute terms, as we did not see significant changes in protein immunoreactivity or subsequent islet vascularization.

The developmental interrelationship between vascularization and islet growth is complex, with multiple factors involved. The islet vascular network provides supporting signals that determine and maintain $\beta$-cell mass not only through regulation of nutrients and substrates but also by supplying signals to induce $\beta$-cell development. Meanwhile, normal $\beta$-cells elaborate angiogenic factors that are required for development of a healthy capillary network vital to the delivery of hormones and the maintenance of normal glucose homeostasis. Disruption of either of these- $\beta$-cell mass or vascularization - can have a lasting and substantial impact on glucose homeostasis and the development of diabetes. The improvement in islet vascularization induced by Ex-4 treatment in the IUGR model suggests that the modulation of islet vascularity may represent a therapeutic approach to prevention of diabetes.

Acknowledgments. We thank Hongshun Niu, Nankong Hong, and David Groff for technical assistance, and Göran Mattson of Uppsala University for providing the BS1 staining protocol.

\section{REFERENCES}

1. Fernandez-Twinn DS, Ozanne SE 2006 Mechanisms by which poor early growth programs type- 2 diabetes, obesity and the metabolic syndrome. Physiol Behav 88:234-243

2. Simmons RA, Templeton LJ, Gertz SJ 2001 Intrauterine growth retardation leads to the development of type 2 diabetes in the rat. Diabetes 50:2279-2286

3. Finegood DT, Scaglia L, Bonner-Weir S 1995 Dynamics of beta-cell mass in the growing rat pancreas. Estimation with a simple mathematical model. Diabetes 44:249-256

4. Scaglia L, Cahill CJ, Finegood DT, Bonner-Weir S 1997 Apoptosis participates in the remodeling of the endocrine pancreas in the neonatal rat. Endocrinology 138:1736-1741

5. De Leon DD, Crutchlow MF, Ham JY, Stoffers DA 2006 Role of glucagon-like peptide- 1 in the pathogenesis and treatment of diabetes mellitus. Int J Biochem Cell Biol 38:845-859

6. Stoffers DA, Desai BM, DeLeon DD, Simmons RA 2003 Neonatal exendin-4 prevents the development of diabetes in the intrauterine growth retarded rat. Diabetes 52:734-740

7. Konstantinova I, Lammert E 2004 Microvascular development: learning from pancreatic islets. Bioessays 26:1069-1075

8. Yoshitomi H, Zaret KS 2004 Endothelial cell interactions initiate dorsal pancreas development by selectively inducing the transcription factor Ptfla. Development 131:807-817

9. Lammert E, Cleaver O, Melton D 2001 Induction of pancreatic differentiation by signals from blood vessels. Science 294:564-567

10. Boujendar S, Arany E, Hill D, Remacle C, Reusens B 2003 Taurine supplementation of a low protein diet fed to rat dams normalizes the vascularization of the fetal endocrine pancreas. J Nutr 133:2820-2825

11. Christofori G, Naik P, Hanahan D 1995 Vascular endothelial growth factor and its receptors, flt- 1 and flk-1, are expressed in normal pancreatic islets and throughout islet cell tumorigenesis. Mol Endocrinol 9:1760-1770

12. Vasir B, Jonas JC, Steil GM, Hollister-Lock J, Hasenkamp W, Sharma A, BonnerWeir S, Weir GC 2001 Gene expression of VEGF and its receptors Flk-1/KDR and Flt-1 in cultured and transplanted rat islets. Transplantation 71:924-935

13. Brissova M, Shostak A, Shiota M, Wiebe PO, Poffenberger G, Kantz J, Chen Z, Carr C, Jerome WG, Chen J, Baldwin HS, Nicholson W, Bader DM, Jetton T, Gannon M, Powers AC 2006 Pancreatic islet production of vascular endothelial growth factor-a is essential for islet vascularization, revascularization, and function. Diabetes 55:2974-2985

14. Lammert E, Gu G, McLaughlin M, Brown D, Brekken R, Murtaugh LC, Gerber HP, Ferrara N, Melton DA 2003 Role of VEGF-A in vascularization of pancreatic islets. Curr Biol 13:1070-1074

15. Mattsson G, Jansson L, Carlsson PO 2002 Decreased vascular density in mouse pancreatic islets after transplantation. Diabetes 51:1362-1366

16. De Leon DD, Farzad C, Crutchlow MF, Brestelli J, Tobias J, Kaestner KH, Stoffers DA 2006 Identification of transcriptional targets during pancreatic growth after partial pancreatectomy and exendin-4 treatment. Physiol Genomics 24:133-143

17. Kuroda M, Oka T, Oka Y, Yamochi T, Ohtsubo K, Mori S, Watanabe T, Machinami R, Ohnishi S 1995 Colocalization of vascular endothelial growth factor (vascular permeability factor) and insulin in pancreatic islet cells. J Clin Endocrinol Metab 80:3196-3200

18. Li X, Zhang L, Meshinchi S, Dias-Leme C, Raffin D, Johnson JD, Treutelaar MK, Burant CF 2006 Islet microvasculature in islet hyperplasia and failure in a model of type 2 diabetes. Diabetes 55:2965-2973

19. Ferrara N 2004 Vascular endothelial growth factor: basic science and clinical progress. Endocr Rev 25:581-611

20. Vasir B, Aiello LP, Yoon KH, Quickel RR, Bonner-Weir S, Weir GC 1998 Hypoxia induces vascular endothelial growth factor gene and protein expression in cultured rat islet cells. Diabetes 47:1894-1903

21. Nikolova G, Jabs N, Konstantinova I, Domogatskaya A, Tryggvason K, Sorokin L, Fassler R, Gu G, Gerber HP, Ferrara N, Melton DA, Lammert E 2006 The vascular basement membrane: a niche for insulin gene expression and Beta cell proliferation. Dev Cell 10:397-405

22. Duvillie B, Currie C, Chrones T, Bucchini D, Jami J, Joshi RL, Hill DJ 2002 Increased islet cell proliferation, decreased apoptosis, and greater vascularization leading to beta-cell hyperplasia in mutant mice lacking insulin. Endocrinology 143:1530-1537

23. Robinson CJ, Stringer SE 2001 The splice variants of vascular endothelial growth factor (VEGF) and their receptors. J Cell Sci 114:853-865

24. Ladomery MR, Harper SJ, Bates DO 2007 Alternative splicing in angiogenesis: the vascular endothelial growth factor paradigm. Cancer Lett 249:133-142 